\title{
EDITORIAL \\ The Klüver-Bucy syndrome and the golden age of localization
}

\author{
Chris A. Sloffer, MD, MBA \\ Bronson Neuroscience Center, and Western Michigan University Homer Stryker School of Medicine, Kalamazoo, Michigan
}

$\mathrm{T}$ He Klüver-Bucy syndrome is an iconic condition that all residents in neurosurgery and neurology learn about, and it is a frequent topic of questions on examinations. Like many iconic syndromes, it is uncommon-even rare-in clinical practice. A wider historical view would argue, however, that the specter of KlüverBucy syndrome drove some of the techniques in temporal lobectomy as that procedure developed. Thus, although rarely seen today, it has had a lasting influence on the discipline.

Vannemreddy and Stone have reported that the experiments of Heinrich Klüver and Paul Bucy, which were carefully conducted, meticulously tested, and elegantly reported, were in fact a reprisal of the work of Sanger Brown and Sir Edward Schäfer from a half century earlier. ${ }^{6}$ The authors do not make a question of primacy, nor do they detract credit from Klüver and Bucy. It appears that Klüver and Bucy did not know of the prior work for several years after publication of their observations. Vannemreddy and Stone nicely describe Brown and Schäfer's work from the "golden age" of cerebral localization in England in the late 19 th century, and discuss some of the interactions between Schäfer and others working in the field at that time.

There had been a long debate on whether the brain had identifiable locations corresponding to specific functions, or whether the brain's functions were more global in nature. The "localizers" had taken the work of Paul Broca ${ }^{1}$ as well as Gustav Fritsch and Eduard Hitzig ${ }^{4}$ as evidence of the existence of localization, and put it to an experimental test. Sir David Ferrier emerged as the leader of the localizers, with his elegant experiments of brain stimulation and lesioning in animals ranging from pigeons to primates. He publicized his conclusions in his seminal 1876 text, Functions of the Brain. ${ }^{2}$ The opponents of localization were largely represented by Friedrich Goltz, who argued for a more unitary organization of brain function. The culmina- tion of the debate came with opposing presentations at the 1881 International Medical Conference, where the experimental animals displayed were presented, then subjected to necropsy and evaluation by William Gowers, who served as a de facto referee. When the lesions in the brain of Ferrier's animal proved to be exactly as he described, and Goltz's animal proved to have a more limited lesion than he had claimed, it was seen as a victory for Ferrier, and in general was a watershed moment in the acceptance of the concept of localization of brain function.

This was the context in which Brown and Schäfer did their experimentation with temporal lobectomy. The disagreement between Schäfer and Ferrier is fascinating from a historical standpoint. Ferrier had just published a second, and heavily revised, edition of his book and was at the height of his reputation in 1888, when Schäfer and Brown published their work. Schäfer was a young physiologist, but not without a rising star of his own. He had been elected to the Royal Society in 1878 at 28 years of age. He was appointed Fullerian Professor of Physiology in that same year, where he followed in the footsteps of Michael Foster and Thomas Huxley in a position later held by Victor Horsley and Charles Sherrington.

If the reason for Ferrier's visceral reaction to Schäfer's work is known, it has escaped my reading. By most accounts, Ferrier was of a genial sort. He was also, however, parsimonious in credit given to Fritsch and Hitzig for their discovery that electrical stimulation of the brain could lead to reproducible motor movements in the dog. For example, when reviewing Hitzig's later experiments that confirmed some but not all of his own work, he wrote: "These discrepancies which Hitzig discovers do not exist in reality, but only in his own method of reading the facts." ${ }^{\prime}$ Although he was supportive of the research of others, for example as one of the founders of the journal Brain, perhaps he was less accepting of criticism of his 
own work. It is interesting that time judged that Ferrier's criticism was unfounded; Ferrier's errors in localization of the visual and auditory pathways and cortex are well known. ${ }^{2,3}$ It may have fallen to Heinrich Klüver in the next century, with his more refined testing methods, to explain the visual loss with temporal lobe injury.

The second half of the 19th century was a period of experimentation that anatomically confirmed clinical impressions and solidified the concept of localization of function within the brain. This idea of localization set the stage for meaningful brain surgery in the coming years. It is not a coincidence that Ferrier's localization work took place in the 1870s and that Bennett and Godlee's first successful tumor case followed in 1884. Vannemreddy and Stone have nicely shown that a series of famous experiments by the next generation of investigators can be linked to a previous age. Klüver and Bucy were able to make more accurate and lasting inferences due to the improvement in both surgical techniques and in animal testing. I commend the authors on bringing this link to the age of localization to our attention, and especially for shedding light on the conflict between Schäfer and Ferrier, which serves to help us better understand the historical context of late-19th-century neurology and neurophysiology. The localization of function that originated in those decades set the stage for the development of our specialty, and con- tinues to serve as the touchstone of neurology and neurosurgery.

https://thejns.org/doi/abs/10.3171/2017.6.FOCUS17416

\section{References}

1. Broca P: Remarques sur le siège de la faculté du langage articulé; suivies d'une observation d'aphémie (perte de la parole)., 1861, in Von Bonin G (ed): Some Papers on the Cerebral Cortex. Springfield, IL: Charles C Thomas, 1960, pp 49-72

2. Ferrier D: Functions of the Brain. London: Smith, Elder, $1876, \mathrm{p} 74$

3. Fishman RS: Ferrier's mistake revisited, or when it comes to the brain, nothing is simple. Arch Neurol 52:725-730, 1995

4. Fritsch G, Hitzig E: Über die elektrische Erregbarkeit des Grosshirns, 1870, in Von Bonin G (ed): Some Papers on the Cerebral Cortex. Springfield, IL: Charles C Thomas, 1960, pp 73-96

5. Heffner HE: Ferrier and the study of the auditory cortex. Arch Neurol 44:218-221, 1987

6. Vannemreddy PSSV, Stone JL: Sanger Brown and Edward Schäfer before Heinrich Klüver and Paul Bucy: their observations on bilateral temporal lobe ablations. Neurosurg Focus 43(3):E2, 2017

\section{Disclosures}

The author reports no conflict of interest. 